\title{
A PRELIMINARY PERSPECTIVE OF THE 50-YEAR PUBLICATIONS IN THE JOURNAL OF COMPUTER INFORMATION SYSTEMS
}

\author{
Monica C. Holmes, Central Michigan University, monica.c.holmes@ cmich.edu \\ Roger L. Hayen, Central Michigan University, hayen1rl@cmich.edu
}

\begin{abstract}
The Journal of Computer Information Systems (JCIS) celebrates its $50^{\text {th }}$ anniversary issue in 2010. This paper examines the inception of this journal and attempts to walk in the footsteps of its predecessors, the Data Processor (DE) and the Journal of Data Education (JDE). The keywords used to categorize the articles published in these journals were surfaced and analyzed to provide a time line of the evolution of the Information Technology (IT)/Information Systems (IS) disciplines. While this study has its limitations, it does provide an initial insight into the process of IT maturity.

Keywords: DSS, history, information systems research, JCIS
\end{abstract}

\section{INTRODUCTION}

The disciplines of IT and IS have progressed from the infancy of data processing (DP) in the past half of a century. Much of that transformation is captured in the pages of the JCIS. Studies of the topics published under IS research have been done over the years. An exploration of the history of journals and associations generally demonstrates the journey that a discipline(s) would take to its contemporary position. The papers published in these journals could also be seen to have evolved with the communities that read them. For many authors that conduct research into important IT or IS topics, this perspective does not necessarily or easily emerge. Hence, the authors believe that this project provides a valuable insight into the evolution of the research in IT/IS today. This paper is an investigation of the research topics published in JCIS, and its predecessors, DE and the JDE over the past 50 years.

\section{BACKGROUND}

In 2010, JCIS celebrates its $50^{\text {th }}$ anniversary of publication. The fifty years since 1961 have seen many changes in our society, including the research topics published by the journal. In the late 1950s and early 1960s, automation had only just begun to gain importance, both in business and in business education. Today, computers are a commodity, and social media is seen as a necessity for people and businesses to be connected. Society, both for business and on a personal level, uses social media tools such as facebook, twitter, plaxo, and linkedin.com to name a few, to connect with each other and to promote news and events. Often there is a mismatch between the technological expectations of the students and the use of technical tools by their instructors, thus giving rise to classroom conflicts. Perhaps this paper will provide a better understanding of how technologies change and how human behavior, especially in pedagogy, react to these changes, will help to minimize such conflicts.

\section{METHODOLOGY}

A review of JCIS since the publication of its first issue was examined at a Midwestern regional university. Early issues were kept in microfiche at the library. Later issues were in print. However, issues of the journal for the period, 1983-1985 were missing from the libraries and the authors were not able to obtain these issues from other sources. The librarian was not able to provide any information as to why they were missing. A thorough review of the available articles was conducted and an extraction of the keywords used through the five decades was completed. Keywords were not provided by earlier issues of the journal and hence, the authors had to use their discretion when reviewing the articles. A list of keywords that were most frequently used over the 50 years was also extracted from the articles published. Where possible, topics were identified the first year they were published. The authors had to be somewhat subjective in the selection of the keywords used. Therefore, the reader is encouraged to keep this limitation in mind. Although numerous issues of the journals were examined, because of the lack of space, only the most critical references are listed at the end of this paper.

\section{HISTORY OF THE JOURNALS AND THE ASSOCIATIONS}

A study of the evolution of JCIS shows that changes in the journal were paralleled by the changes in the associations affiliated with it. Most significant was 
the shift from a focus on the teaching of business education in high schools and colleges to that on the usage of computers and technologies in business. Membership in the association also shifted from teachers in high schools to instructors and professors at community colleges and universities. Authorship of articles published in the JCIS also now often includes corporate representatives, a feature that brings real business problems into classroom discussion and thus impacts business curriculum.

The Society for Automation in Business Education (SABE-1) published the first issue of the Data Processor (DP) on January 1961 [1]. Members of SABE were charged with the promotion of "the growth and development of knowledge and understanding of automation among business teachers and other interested parties" [1]. The second issue of the DP was published in February 1961 with similar topics [2]. Henceforth, the DP was published on a monthly basis, from October to May, with the membership dues at $\$ 2$ a year.

In 1968, the DP became the Journal of Data Education (JDE). The first issue was Volume IX No. 1 October 1968 [4]. At the same time, the SABE-1 became the Society for Automating Better Education (SABE-2). Dr. Enoch Haga was the President of the society and Robert Kriegbaum was the editor of the JDE. At this time, there was a call to encourage colleagues in business education to reach out to their peers in similar fields to join SABE-1. There were four articles and eight editorial topics with the President's message (Appendix A). The JDE was published on a monthly basis, from October to May. Members of the editorial board were faculty members of universities and colleges as well as high schools. The next section discusses the first issues of DP, JDE and JCIS.

\section{LANDMARK PUBLICATIONS}

The inaugural issue of the DP [1] contained the following topics: a message from the Editor, Dr. Enoch J. Haga, a list of books, magazines, and other publications "worth reading," a list of meetings worth attending, what others are doing, new ideas, a list of theses and dissertations on automation, and finally, one article for teachers, "The Meaning of Systems," by Dr. E. Dana Gibson. The message from Dr. Haga extolled the members of SABE to promote the society, get other professional organizations to evaluate automation at their meetings, and to submit "data and ideas" for publication in DP.
The second issue of the DP [2] was published in February 1961 with similar topics. An important item was the nomination of the officers for SABECalifornia Business Education Association; i.e., President - Dr. E. Dana Gibson, Vice-President - Dr. William Selden, and Chief Editor - Dr. Enoch J. Naga. In this issue, the article for teachers continued the theme of systems, i.e., the Interrelationship of Systems and Machines. These two issues of DP clearly attempted to be useful to its readers, i.e., teachers of business education classes, either in high schools, community colleges or universities.

In October, 1968, the first issue of the JDE [4] was published with the following topics: President's message, book reviews, Ideas for Teachers, Automation Scrapbook, Introducing Two New Services, Automation Research, Audio-Visual Aids, SABE's Big Leap Forward, and the New Federated Societies, "Computer Controlled Learning, "A Little Computer Does a Big College Job," "Help Others Learn More About Automation," and "More Automation for All Teachers Needed".

The second issue of the JDE [5], had similar contents: President's Message, the SABE National (S)Election, an Automation-Supported Instructional System, Convention Plans, Audio-Visual Aids, The Society for Automation in Professional Education, Improving Students' Notes, Presidents of the Federated Societies, Applications with discussions on "Terminals Extend Users' Thoughts," "Automated Grade Reporting with Optical Scanner," and "Data Collection Systems Helps UCLA Library Cope," Automation Scrapbook, and "Opinion - End of the Beginning" by Enoch Haga. The scope of the JDE had expanded to include data automation topics to help companies with their problems.

Although the JDE from 1973 to 1988 was available at CMU, unfortunately, the issues from late 1982 to 1985 were missing. The authors had not been able to obtain these missing issues at the time of publication. This is a limitation in this study.

The first issue of the JCIS was published in fall 1986 [6]. It was being published four times a year with Dr. Jeretta Nord as the Editor. Dr. Susan D. Haugen was the President of the Society of Data Educator for 1986-1988. Dr. Cynthia Johnson was the VicePresident and Dr. Gary Armstrong was the Secretary. The treasurer, the Past President, the Managing Director of the Society and the Advertising Manager of the Journal were Drs. Ben Bauman, Robert C. Tesch, Sr., Daryl Nord and William H. Moates respectively. The table of contents include the 
President's Column, six articles and one research article as well as a book review section. The membership dues for the Society of Data Educators were $\$ 25$ a year.

An important event, the last meeting of the ACE was held on October 5, 1990 with the International Association of the Computer Information Systems taking over then. The first board of IACIS were Dr. Tom Seymour - President, Betty Kleen - VicePresident, and Ben Bauman - Treasurer. Membership dues were increased to $\$ 35$ a year. Table 1 below summarizes the evolution of the journals and the associations affiliated with them.

\section{ANALYSIS AND DISCUSSION}

This section discusses the keyword extracted from the journals that were reviewed. Publications during the period from 1961 to September 1972 generally did not have keywords. In addition, the microfiche copies were usually not readable and the authors had difficulties deciphering the articles to categorize them by keywords. However, it was possible, to some extent, to identify certain themes that permeate throughout the 50 years of IT/IS publication. Education and curriculum were issues that were present since the first issue of DP. Case studies of the use of computers in companies were a consistent theme; e.g., the first issue of DP in 1961 published a case study on magazine subscription operation [1]. At the same time, the authors had great difficulties reading some of the articles because of the poor quality of the microfiches available.

Table 1: Journals and Associations

\begin{tabular}{|l|l|l|l|}
\hline Title of Journal/Name of organization & $\begin{array}{l}\text { Membership } \\
\text { Dues }\end{array}$ & $\begin{array}{l}\text { Year } \\
\text { Established }\end{array}$ & $\begin{array}{l}\text { Year Title was first } \\
\text { published/Frequencies of } \\
\text { publication }\end{array}$ \\
\hline Society of Automation in Business Education & $\$ 2$ & & \\
\hline Data Processor & & & January 1961/Monthly \\
\hline Society of Automating Better Education & $\$ 25$ & $\begin{array}{l}\text { October } \\
1968\end{array}$ & \\
\hline Journal of Data Education & & & October 1968/Monthly \\
\hline Journal of Computer Information Systems & & Fall 1990 & Fall 1986/Four times a year \\
\hline $\begin{array}{l}\text { International Association of Computer } \\
\text { Information Systems }\end{array}$ & $\$ 35$ & & \\
\hline
\end{tabular}

Hence, for this paper, the keyword analysis mainly covers the period from October 1972 to Spring 2010. Where keywords were missing in this period, the authors had to use their own judgment to categorize the articles that were published. Consequently, there is some subjectivity in the final evaluation of keywords. First, the keywords were organized in three approximately ten-year slots: October 1972 to July 1982, Fall 1986 to summer 1996, fall 1996 to winter 2006, and one three-year period: spring 2006 to summer 2009. The last period is spring 2009 to spring 2010. The reason for doing this was an attempt by the authors to capture the speed with which the topics changed or persisted. The last 10 to 15 years have had not only a rapid change in the speed of computers and the size of storage devices but also a corresponding dramatic application perspective of how computer applications can be used to enhance business and human environment.

During the period from October 1972 to July 1982, articles were published on education, curriculum, DSS, programming languages and systems tools and techniques. The programming languages included BASIC, COBOL, FORTRAN and PL/1. Data processing had been discussed in earlier years and continued to be popular during this time period. Database, algorithms and interfaces were the more technical issues being published. Case studies were regularly highlighted.

From Fall 1986 to summer 1996, DSS articles were published and so were papers on IS curriculum and artificial intelligence. The topics, systems life cycle and the World-Wide Web (WWW) appeared for the first time [11]. Curriculum research, as it is related to the standards required by DPMA and AACSB, were published several times. It can be seen from the keywords that human behavior, as it related to the use of computers, became more critical as efficiency and effectiveness became the popular theme in the business world.

During the period from Fall 1996 to Winter 2006, ERP became a 'hot' topic as Multinational Corporations (MNCs) embarked on the implementation of huge integrated ISs. These MNCs needed to garner the cost saving potential inherent in duplicate or inefficient systems present in their locations globally. The computing environment, 
leading from 1996 to 2000, was also compounded by the projected consequences that could materialize with the Y2K horizon. Computer security and reliability, software reliability and network issues were important. Companies took advantage of the opportunity to replace legacy systems with ERPs where possible. Others implemented work-around systems where needed. ERP-related topics such as MRP appeared in winter 00/01 issue with telecommunication and systems development appearing several times. Database, data warehouse, DSS and curriculum continue to be published. Distance Learning also appeared for the first time in early 2000 [3].

ERP, knowledge management, systems development, $\mathrm{HCI}$ and IS curriculum continue to be of interest to the members of IACIS during the period of Spring 2006 to the Summer of 2009. It was during this time that telehealth and health informatics as well as RFID began appearing in JCIS [8]. The keywords, project management and Green IT, appeared in summer 2009. DSS and data warehousing were also popular keywords.

During the period, Spring 2009 to Summer 2009, project management and security appeared frequently in JCIS. These two topics aligned well with the thrust in the business world, where projects are typically over budget and seldom on time. Computer security and identity theft became critical

Table 2: The Five Time Periods

\begin{tabular}{|l|l|}
\hline \multicolumn{1}{|c|}{ Time Period } & \multicolumn{1}{c|}{ Keywords } \\
\hline October 1972 - July 1982 & $\begin{array}{l}\text { DSS, programming languages (BASIC, COBOL, FORTRAN \& PL/1), } \\
\text { systems tools \& techniques }\end{array}$ \\
\hline Fall 1986 - Summer 1996 & $\begin{array}{l}\text { DSS, IS Curriculum, artificial intelligence, systems life cycle, WWW, } \\
\text { ERP, distance learning }\end{array}$ \\
\hline Fall 1996 - Winter 2006 & $\begin{array}{l}\text { ERP \& ERP-related topics (MRP), telecommunications and networking, } \\
\text { database, data warehouse }\end{array}$ \\
\hline Spring 2006 - Summer 2009 & $\begin{array}{l}\text { ERP, knowledge management, IS curriculum, HCI, telehealth \& health } \\
\text { informatics, RFID, project management, Green IT }\end{array}$ \\
\hline Spring 2009 - Spring 2010 & $\begin{array}{l}\text { Project management, security, web analytics, BI, data mining, web } \\
\text { retailing, }\end{array}$ \\
\hline
\end{tabular}
decisions was the premise for the need to "Automating Better Education." However, sophisticated computer technologies were only available in the late 1990s onwards. Thus both issues as more and more people use the Internet to make purchases and pay their bills. The $9 / 11$ disaster has also highlighted the need for better computer security and backup systems.

What are the topics that are consistent throughout the journal over the past 50 years? The top three consistent research/discussion topics were education, curriculum, and DSS. In later years, ERP, the Internet \&web, computer security and social media began surfacing with education, curriculum and DSS persisting. The authors speculate that the use of computers to support the making of better society and the business world have seen a tremendous change in the use of technologies in everyday life, leading to the persistence of DSS as a research topic.

Business-related keywords appear more often after 2000. In the early years, technical keywords were more common. The top 20 research topics are listed in Table 3. Topics that were similar or related are combined as in "Jobs/Outsourcing." For example, outsourcing could be defined as hiring an entity 
Table 3: Top 20 Research Topics

\begin{tabular}{|l|l|c|c|}
\hline No. & Topic & Frequencies & $\begin{array}{c}\text { Year First } \\
\text { Appeared }\end{array}$ \\
\hline 1 & Education/curriculum & 331 & 1961 \\
\hline 2 & MIS & 278 & 1973 \\
\hline 3 & Internet/World Wide Web/electronic commerce & 201 & 1997 \\
\hline 4 & Programming/data processing/software/systems development & 171 & 1972 \\
\hline 5 & Research \& development/knowledge-based/survey research & 170 & 1966 \\
\hline 6 & End users & 146 & 1989 \\
\hline 7 & Computer training/CAI & 109 & 1961 \\
\hline 8 & Database/data administration & 107 & 1977 \\
\hline 9 & Technology adoption & 82 & 1967 \\
\hline 10 & Communications \& LANs & 72 & 1986 \\
\hline 11 & Enterprise resources planning & 59 & 1997 \\
\hline 12 & Computer utilization/control system & 58 & 1961 \\
\hline 13 & Decision support systems & 50 & 1972 \\
\hline 14 & Computer system & 42 & 1973 \\
\hline 15 & Security & 40 & 1997 \\
\hline 16 & Business process & 35 & 1962 \\
\hline 17 & Small business/strategies & 35 & 1965 \\
\hline 18 & Jobs/Outsourcing & 29 & 1961 \\
\hline 19 & Ethical \& privacy issues & 27 & 1968 \\
\hline 20 & Simulations & & 1961 \\
\hline & & 20 & \\
\hline
\end{tabular}

external to a business to complete a computer task or service. In 1961, the Vermont Extension Service and the University of Vermont offered electronic farm accounting services to a group of farmers, who mailed their expenses and receipts to the university. Monthly financial summaries were then mailed back to the farmers and the cost was $\$ 45$ a year [9]. It can be seen that in keeping with the goals of the initial society/association as well as with the current IACIS, education and curriculum were the most popular subject areas. Management IS and the WWW came next. While DSS only showed up 50 times, it was a topic that had appeared in earlier issues and will continue to be a relevant research topic. Most probably, one reason for the persistence of DSS as a research topic is the maturity of the IS discipline and also the continuing emergence of high-end technologies. For example, spatial software has become more sophisticated in recent years and more census-type data are becoming available to the public and researchers. The convergence of these two factors has given rise to DSS tools that provide elegant visual outputs or reports. The relative ease with which data is extracted from one software application and then input into other software applications has also made the integration of different systems much easier. The need to verify the regulatory compliance imposed by the SarbanesOxley ACT of 2002 and the Homeland Security ACT of 2002 has raised the necessity for systems quality and reliability as well as systems controls. It is expected that the new Health Care Reform Act 2010 will also increase the significance of research in IT/IS. It is also highly probable that that the Health Care Reform Act 2010 will require more IT professionals to be hired to work on related issues. 


\section{CONCLUSION}

This study examines the publication journal of the JCIS from the first issue as DE to its current status. While complete and accurate data collection was not possible, enough data was collected to provide a preliminary perspective of the 50 years of activities published in the DE, the JDE and the JCIS. This study illustrates the evolution of the pedagogy in IT/IS, which somewhat parallels the changes in the technologies used in business. Emerging technologies will drive even more changes in the learning environment of IT/IS.

\section{REFERENCES}

[1]. Data Processor (1961). Volume 1 Number 1 January.

[2]. Data Processor (1961). Volume 1 Number 2 February.

[3]. Fox, Karen G. \& Mark N Frolick. (2000). "Evolving learning environments." The Journal of Computer Information Systems, 40(4), 72-76. Retrieved October 15, 2009, from ABI/INFORM Global.

[4]. Journal of Data Education (1968), Volume IX Number 1, October.

[5]. Journal of Data Education (1968), Volume IX No. 1, November.
[6]. Journal of Computer Information Systems (1986), Volume XXVII Number 1, Fall.

[7]. Gibson, Rosemary P. (1961). "Automated Teaching," Data Processor, Volume 1 Number 3, March.

[8]. Matta, V., \& Koonce, D.. (2009). "Semantic Breakdown of RFID Functionality to Support Application Development." The Journal of Computer Information Systems, 49(3), 54-59. Retrieved November 2, 2009, from ABI/INFORM Global.

[9]. Pike, Arthur H. (1961). "Electronic Farm Accounting," Data Processor, Volume 1 Number 4, April.

[10]. Various authors (1990). Journal of Computer Information Systems, Volume XXXI Number 2, Winter 1990-1991.

[11] Vedder, Richard G., Carl S Guynes, \& Michael T Vanecek. (1997). "Electronic commerce on the WWW/Internet." The Journal of Computer Information Systems, 38(1), 20-25. Retrieved October 5, 2009, from ABI/INFORM Global.

[12]. World Future 2010: Sustainable Futures, Strategies, and Technologies (2010). "Preliminary Program," World Future Society, March 30, 2010.

\section{APPENDIX A}

Journal of Data Education, Volume IX No. 1 October 1968

\begin{tabular}{|lc}
\hline & Table of Contents \\
President's Message, Enoch Haga & 3 \\
Book Reviews, Clyde A. Randall & 4 \\
Ideas for Teachers & 5 \\
Automation Scrapbook & 6 \\
Introducing Two New Services & 7 \\
Automation Research, John A. Drenth & 8 \\
Audio-Visual Aids, Mary Robek & 9 \\
SABE's Big Leap Forward, E. Dana Gibson & 10 \\
The New Federated Societies & 11 \\
Computer Controlled Learning, Brother Austin David & 12 \\
A Little Computer Does a Big College Job, Joseph A. Duerstock & 13 \\
Help Others Learn More About Automation & 14 \\
More Automation For All Teachers Needed & 15
\end{tabular}

